\title{
LncRNA CASC19 accelerates chondrocytes apoptosis and proinflammatory cytokine production to exacerbate osteoarthritis development through regulating the miR- 152-3p/DDX6 axis
}

Chang Zhou', Tianda He ${ }^{2}$ and Liji Chen ${ }^{3 *}$

\begin{abstract}
Background: Osteoarthritis $(\mathrm{OA})$ is one kind of degenerative joint disease that happens in articular cartilage and other joint tissues. Long non-coding RNAs (IncRNAs) have been reported to serve as pivotal regulators in many diseases, including OA. However, the role and relevant regulatory mechanisms of CASC19 in OA remain unknown.

Methods: The expression levels of CASC19, miR-152-3p, and DDX6 were identified by reverse-transcription polymerase chain reaction (RT-qPCR). Cell viability and apoptosis were determined by Cell Counting Kit-8 (CCK-8) and flow cytometry assays, respectively. The relationship between miR-152-3p and CASC19 or DDX6 was predicted by bioinformatics tools and verified by the dual-luciferase reporter assay.

Results: CASC19 was verified to exhibit higher expression in OA tissues and cells. Moreover, inhibition of CASC19 weakened proinflammatory cytokine (IL-6, IL-8, and TNF-a) production and cell apoptosis but facilitated cell viability. Experiments of the ceRNA mechanism elucidated that miR-152-3p was a sponge for CASC19, and miR-152-3p targeted DDX6, suggesting that CASC19 sponged miR-152-3p to release DDX6. Finally, results from rescue assays proved that the impacts of CASC19 silencing on chondrocytes apoptosis and proinflammatory cytokine production could be reversed by DDX6 overexpression.

Conclusions: It was concluded that IncRNA CASC19 accelerated chondrocytes apoptosis and proinflammatory cytokine production to exacerbate osteoarthritis development through regulating the miR-152-3p/DDX6 axis. These findings may offer an effective biological target for OA treatment.
\end{abstract}

Keywords: CASC19, miR-152-3p, DDX6, Osteoarthritis

\footnotetext{
*Correspondence: chen_liji1@163.com

${ }^{3}$ Department of Encephalopathy, Changzhou Hospital of Traditional Chinese Medicine, No. 25 Heping North Road, Changzhou 213000, People's Republic of China

Full list of author information is available at the end of the article
}

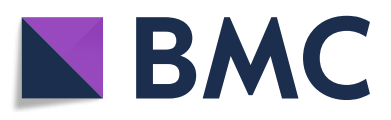

(- The Author(s). 2021 Open Access This article is licensed under a Creative Commons Attribution 4.0 International License, which permits use, sharing, adaptation, distribution and reproduction in any medium or format, as long as you give appropriate credit to the original author(s) and the source, provide a link to the Creative Commons licence, and indicate if changes were made. The images or other third party material in this article are included in the article's Creative Commons licence, unless indicated otherwise in a credit line to the material. If material is not included in the article's Creative Commons licence and your intended use is not permitted by statutory regulation or exceeds the permitted use, you will need to obtain permission directly from the copyright holder. To view a copy of this licence, visit http://creativecommons.org/licenses/by/4.0/ The Creative Commons Public Domain Dedication waiver (http://creativecommons.org/publicdomain/zero/1.0/) applies to the data made available in this article, unless otherwise stated in a credit line to the data. 


\section{Introduction}

Osteoarthritis (OA), one complicated chronic arthropathy characterized by local inflammation and articular cartilage damage and degradation, is one primary cause of disability in the elderly $[1,2]$. At present, OA has become a great threat to public health worldwide, and almost $10 \%$ of the population and $50 \%$ of people aged above 65 suffer from OA [3, 4]. Hence, it is urgent to extend the knowledge of OA pathology and develop more effective therapeutic strategies. Aberrant apoptosis, extracellular matrix, and inflammatory response of chondrocytes are related to cartilage degradation in OA [5, 6]. Therefore, in-depth exploration of chondrocytedysfunction-related mechanisms may help to enhance understanding of OA pathogenesis.

Long non-coding RNAs (lncRNAs) are RNAs with more than 200 nucleotides in length and have no protein-coding ability [7-9]. These lncRNAs function as important regulators in multiple diseases, including OA. For example, IncRNA TM1P3 regulates chondrocyte extracellular matrix degradation to participate in OA progression [10]. LncRNA PVT1 absorbs miR488-3p in OA to modulate chondrocyte apoptosis [11]. LncRNA ZFAS1 regulates cellular processes of chondrocytes in OA [12]. In addition, IncRNA H19 suppression modulates miR-130a in OA to improve LPS-induced damage [13]. CASC19, one of the recently identified IncRNA, has been demonstrated to participate in various cancers. For example, IncRNA CASC19 absorbs miR-301b-3p to modulate LDLR and accelerates non-small cell lung cancer tumorigenesis [14]. LncRNA CASC19/miR-454-3p/RAB5A axis to facilitate glioma progression [15]. Besides, lncRNA CASC19 targets miR-148b/E2F7 axis to aggravate pancreatic cancer progression [16]. LncRNA CASC2 was found to promote $\mathrm{OA}$ progression via regulating IL-17 expression [17]. Therefore, we assumed that CASC19, another IncRNA of the cancer susceptibility candidate (CASC) family, might also be involved in $\mathrm{OA}$ development. However, the function and regulatory mechanisms of CASC19 in OA are still unclear.

MicroRNAs (miRNAs), another kind of non-coding RNAs with about 18-22 nucleotides, can regulate cell phenotypes, such as cell proliferation, apoptosis, and differentiation [18-20]. Recent investigations have revealed the vital function of miR-152-3p in diseases. For instance, miR-152-3p targets FOXF1 to modulate keloid fibroblast development [21]. Furthermore, miR-152-3p targets CDK8 to regulate hepatic carcinogenesis [22]. CircHIPK3 sponges miR-152-3p to release TGF- $\beta 2$, thus promoting cardiac fibrosis under hypoxia by regulating fibroblast proliferation and phenotypic switching [23]. Additionally, miR-152 regulates TCF-4 pathway in OA rats to weaken chondrocyte apoptosis and cartilage degeneration [24]. StarBase website predicted that miR152-3p owned putative complementary sites for CASC19. Nevertheless, the association between miR152-3p and CASC19 in OA maintains unknown.

In this study, we intended to investigate the functions and potential regulatory mechanism of CASC19 in OA. Findings in this study revealed that CASC19 accelerated chondrocyte apoptosis and proinflammatory cytokine production to exacerbate $\mathrm{OA}$ development through regulating miR-152-3p/DDX6 axis, suggesting that CASC19 might be a new target for OA treatment.

\section{Materials and methods}

\section{Patients and specimens}

A total of 40 samples were respectively collected from 20 patients with OA and 20 trauma patients (undergoing lower-extremity amputation) without OA. Patients meeting the diagnostic criteria for OA were included in the study, while patients complicated with other diseases, such as history of joint surgery or rheumatoid arthritis were excluded. The general clinical characteristics of 20 OA patients and 20 trauma patients without OA (control group) were illustrated in Table 1. According to the data acquired, OA and control groups were homogeneous in age, gender, and BMI. For OA patients, total knee arthroplasty was performed and the cartilage of knee joints was taken. For trauma patients, the normal articular cartilage of knee joints was also obtained after lower-extremity amputation according to relevant studies $[25,26]$. Informed consent was acquired from all participators. This study was supported by the Human Ethics Committee of Changzhou Hospital of Traditional Chinese Medicine.

Table 1 Comparison of clinical characteristics between OA patients and the control group

\begin{tabular}{|c|c|c|c|}
\hline & OA group $(n=20)$ & Control group $(n=20)$ & $P$ value \\
\hline \multicolumn{4}{|l|}{ Gender } \\
\hline Male & 11 & 10 & 0.64 \\
\hline Female & 9 & 10 & \\
\hline \multicolumn{4}{|l|}{ Age } \\
\hline$<60$ & 13 & 14 & 0.07 \\
\hline$\geq 60$ & 7 & 6 & \\
\hline \multicolumn{4}{|c|}{ BMI $\left(\mathrm{kg} / \mathrm{m}^{2}\right)$} \\
\hline$<24$ & 7 & 8 & 0.12 \\
\hline$\geq 24$ & 13 & 12 & \\
\hline \multicolumn{4}{|c|}{ Kellgren-Lawrence grading } \\
\hline 2 & 8 & & \\
\hline 3 & 7 & & \\
\hline 4 & 5 & & \\
\hline
\end{tabular}


Cell culture

The human chondrocytes C28/I2 cells (ATCC, Manassas, VA) were maintained in Dulbecco's modified Eagle's medium (DMEM; Gibco, USA) with 10\% fetal bovine serum. All cells were maintained at $37{ }^{\circ} \mathrm{C}$, and $5 \% \mathrm{CO}_{2}$. For establishing the OA model, C28/I2 cells were stimulated with IL-1 $\beta(10 \mathrm{ng} / \mathrm{ml})$.

\section{Cell transfection}

Short hair RNAs (shRNA) against CASC19 (sh-CASC19) and negative control (sh-NC) were bought from GenePharm (Shanghai, China). MiR-152-3p mimics and NC mimics were also acquired from GenePharm. The DDX6 vectors (oe-DDX6) were constructed by cloning its 3'UTR into the pcDNA3.1 vectors (Thermo Fisher Scientific). The transfection for these vectors was carried out by Lipofectamine 2000 (Thermo Fisher Scientific).

\section{Reverse-transcription polymerase chain reaction (RT- qPCR)}

RNAs were extracted from C28/I2 cells or OA tissues using Trizol reagent (Invitrogen, CA, USA). Synthesis of cDNA was performed with the PrimeScript ${ }^{\circ} \mathrm{RT}$ reagent Kit (Takara, Dalian, China). The PCR was conducted with SYBR Green PCR kit (TaKaRa, Dalian, China) using GAPDH/U6 as endogenous control. The data were processed through the $2^{-\Delta \Delta C t}$ method.

\section{Enzyme-linked immunosorbent assay (ELISA)}

The inflammatory cytokines interleukin-6 (IL-6), interleukin-8 (IL-8), or tumor necrosis factor-alpha (TNF- $\alpha)$ levels were measured through the corresponding Quantikine ELISA Kits (R\&D Systems, Abingdon, UK).

\section{CCK-8 assay}

Cell viability was examined through Cell Counting Kit-8 (CCK-8) (Dojindo, Tokyo, Japan). In short, transfected $\mathrm{C} 28 / \mathrm{I} 2$ cells at a density of $1 \times 10^{4}$ cells/well were seeded on 96-well plates. After 0, 24, 48, 72, and $96 \mathrm{~h}$, CCK-8 solution $(10 \mu \mathrm{l})$ was added into each well, and the cells were incubated for $4 \mathrm{~h}$ at room temperature. The cell viability (at $450 \mathrm{~nm}$ ) was evaluated through the Microplate Reader (Bio-Rad, Hercules, CA, USA).

\section{Flow cytometry assay}

Cell apoptosis was assessed through the Annexin VFITC Apoptosis Detection Kit (Abcam, Cambridge, UK). Generally, after being rinsed twice with cold PBS solution, C28/I2 cells were resuspended. Afterwards, Annexin V-FITC and propidium iodide (PI) were mixed and incubated. Finally, the apoptosis rate was examined under the flow cytometer (BD Biosciences, San Jose, CA, USA).

\section{Luciferase reporter assay}

For luciferase reporter assay, sequences of CASC19 (or DDX6) were inserted into pmirGLO vectors (Promega, Madison, WI, USA) to produce wild-type CASC19 (or DDX6) vectors (CASC19-Wt or DDX6-Wt). The mutant-type CASC19 (or DDX6) vectors (CASC19-Mut or DDX6-Mut) were also obtained. These vectors with miR-152-3p mimics or NC mimics were co-transfected into C28/I2 cells. About 48 h, the luciferase activity was
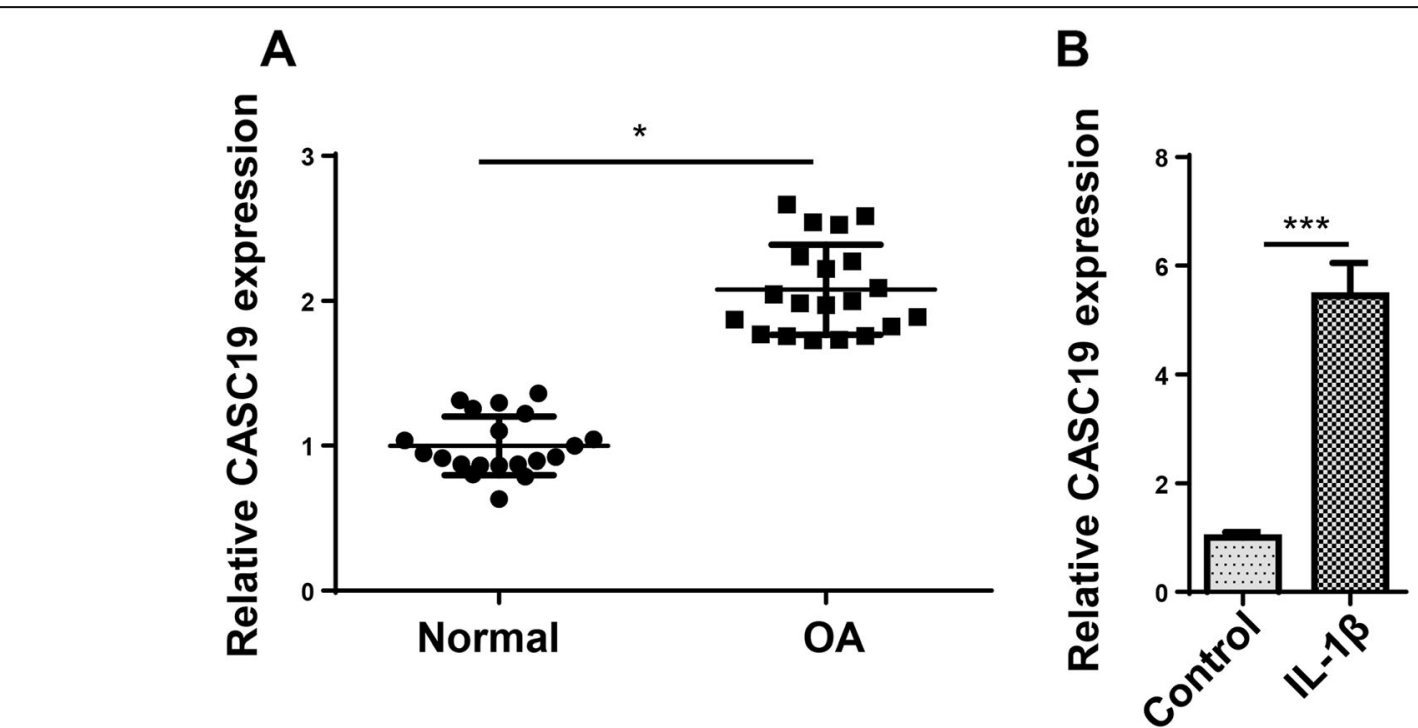

Fig. 1 CASC19 exhibited higher expression in OA tissues and OA cell model. a The CASC19 expression was tested in OA tissues through RT-qPCR assay. $\mathbf{b}$ The expression of CASC19 was detected in C28/I2 cells mediated with IL-1 $\beta$ (10 ng/ml) through RT-qPCR. * $P<0.05$ and ${ }^{* *} P<0.001$ 


\section{A}

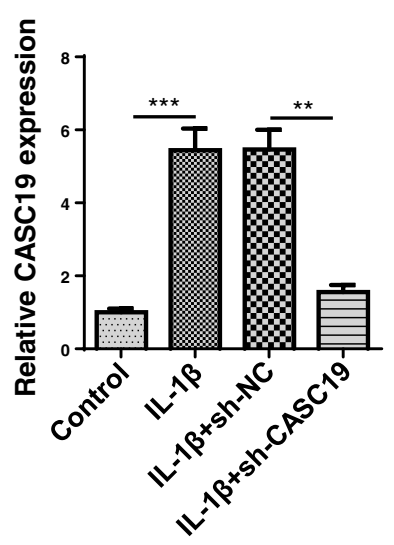

D

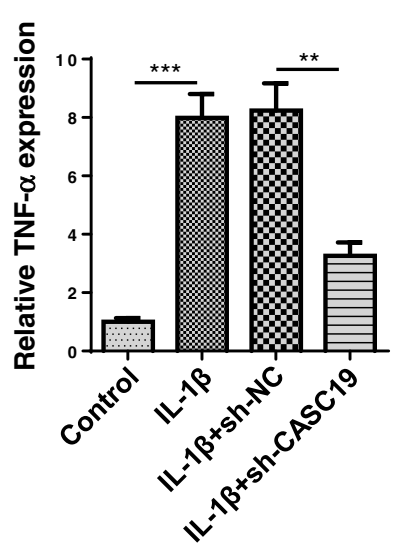

B

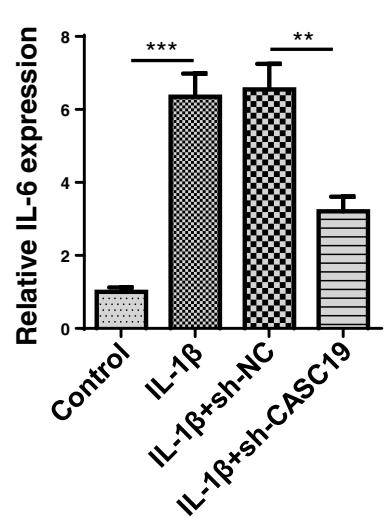

E $\rightarrow$ Control

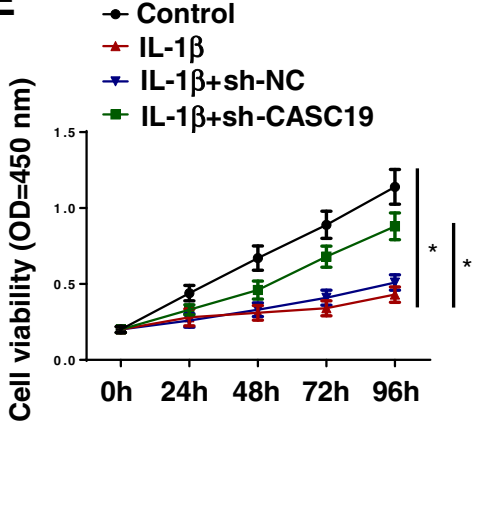

$\mathbf{F}$

Control
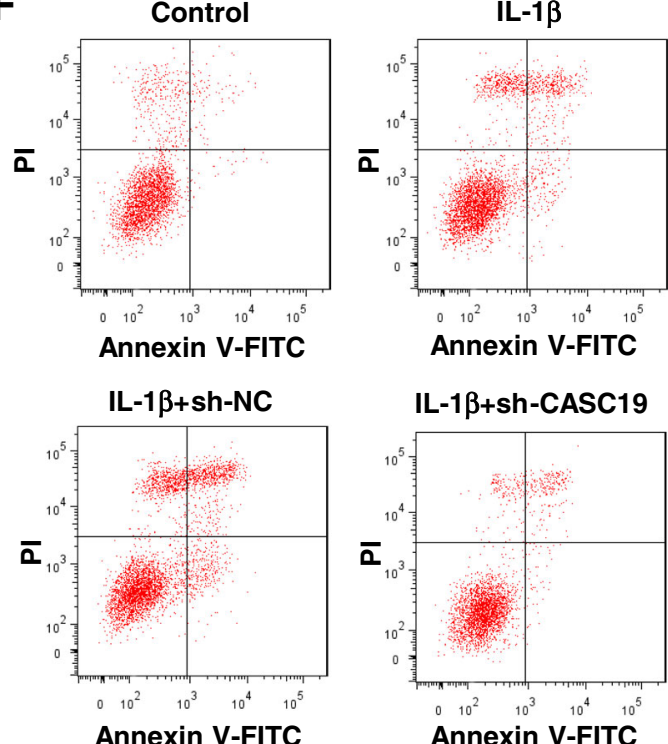

IL-1 $\beta+$ Sh-CASC19
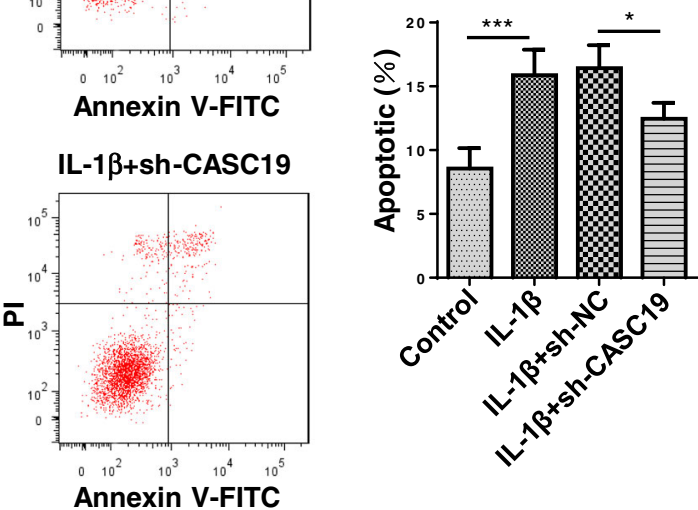

Fig. 2 Inhibition of CASC19 weakened proinflammatory cytokine production and cell apoptosis. a The knockdown efficiency of CASC19 was verified through RT-qPCR. b-d The IL-6, IL-8, and TNF-a levels were tested after silencing CASC19 through ELISA assay. e The cell viability was assessed after suppressing CASC19 through CCK-8 assay. $\mathbf{f}$ The cell apoptosis was detected after CASC19 inhibition through flow cytometry assay. ${ }^{*} P<0.05$, ${ }^{* *} P<0.01$, and ${ }^{* * *} P<0.001$ 
examined through the Dual-Luciferase reporter assay system (Promega).

\section{RNA immunoprecipitation (RIP) assay}

RIP assay was implemented via Magna RIP RNABinding Protein Immunoprecipitation Kit. Cell lysate, RIP buffer, and magnetic beads coupled to Ago2 antibody or normal IgG antibody (as negative control) were mixed. The immunoprecipitated RNA was analyzed through RT-qPCR to quantify gene expression.

\section{Statistical analysis}

Statistical analysis was performed via SPSS 20.0 (SPSS, Inc., Chicago, IL, USA). The data were shown as mean \pm SD. Statistical differences were analyzed through Student's t-test or one-way analysis of variance. $\mathrm{P}<0.05$ was supposed as statistically significant.

\section{Results}

CASC19 exhibited higher expression in OA tissues and cells

CASC19 has been investigated in various cancers [1416], but its role in OA keeps unknown. To probe whether CASC19 is altered in OA, RT-qPCR assay was conducted to test CASC19 expression in OA tissues, and the results indicated that CASC19 exhibited higher expression in OA samples (Fig. 1a). Similarly, CASC19 exhibited higher expression in OA cell model (Fig. 1b). To sum up, CASC19 exhibited higher expression in OA tissues and cell model.

\section{Inhibition of CASC19 inhibited proinflammatory cytokine} production and cell apoptosis

Next, the function of CASC19 in OA progression was explored. CASC19 expression was markedly reduced after suppressing CASC19 in C28/I2 cells mediated with IL-1 $\beta$ (Fig. 2a). The IL-6, IL-8, and TNF- $\alpha$ levels were
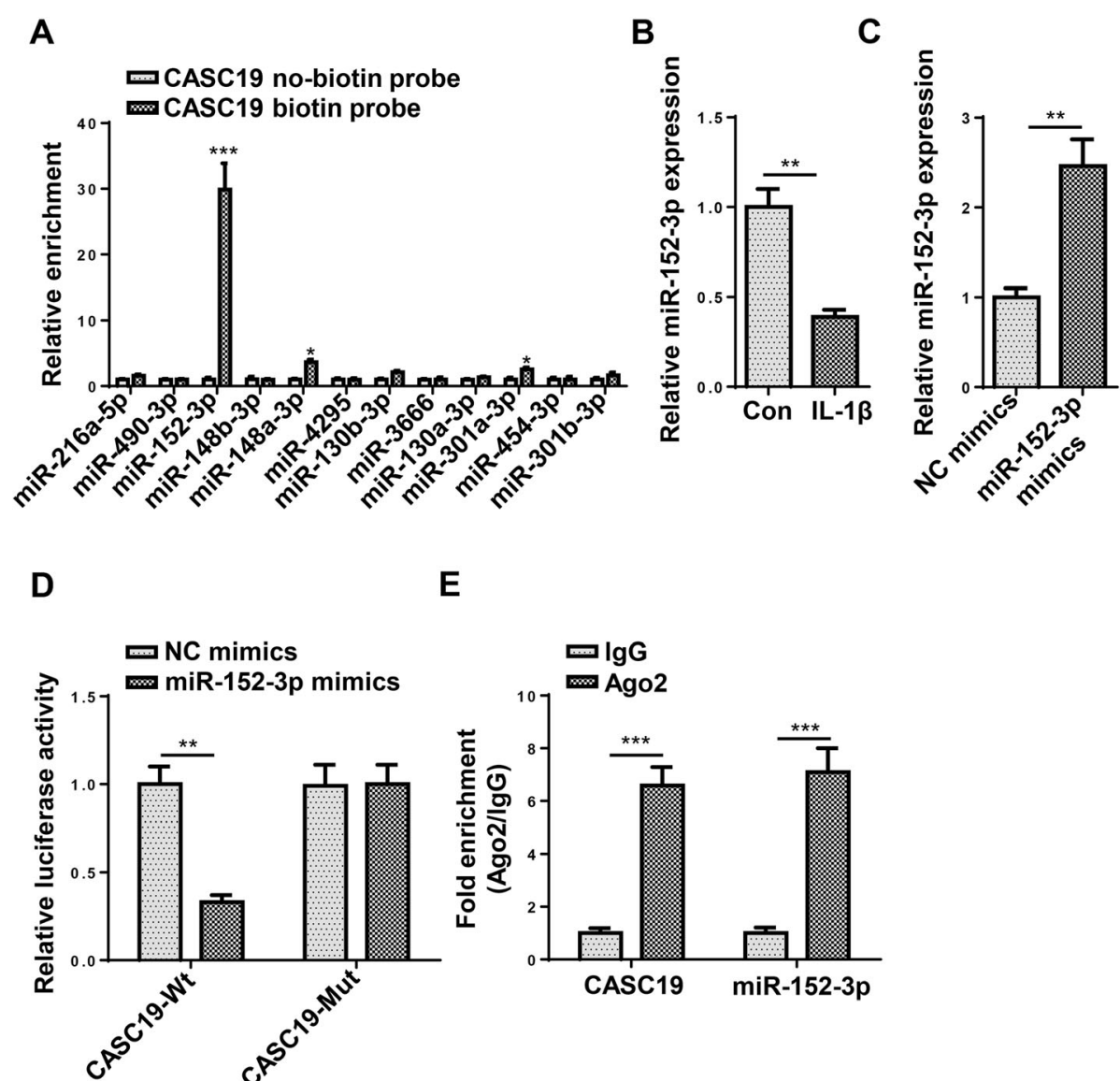

$\mathbf{E}$

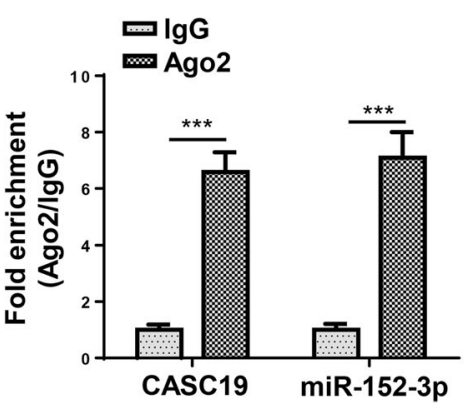

Fig. 3 MiR-152-3p was a sponge for CASC19. a The miRNAs sponged with CASC19 were predicted through starBase website with the condition of CLIP Data: high stringency ( $\geq 3$ ). The binding ability between CASC19 and miRNAs was tested by RNA pull-down assay. $\mathbf{b}$ The miR-152-3p expression was verified through RT-qPCR assay. $\mathbf{c}$ The overexpression efficiency of miR-152-3p was identified through RT-qPCR assay. $\mathbf{d}$ The binding ability between CASC19 and miR-152-3p was confirmed through luciferase reporter assay. e The binding ability between CASC19 and miR-152-3p was assessed through RIP assay. ${ }^{*} P<0.05,{ }^{* *} P<0.01$, and ${ }^{* * *} P<0.001$ 
reduced through silencing CASC19 (Fig. 2b-d). In addition, the cell viability was increased by CASC19 knockdown (Fig. 2e). Through flow cytometry analysis, it was confirmed that CASC19 suppression retarded cell apoptosis (Fig. 2f). These findings suggested that inhibition of CASC19 inhibited proinflammatory cytokine production and cell apoptosis in OA.

\section{MiR-152-3p was a sponge for CASC19}

Subsequently, we investigated the ceRNA mechanism related to CASC19. Through StarBase website, several miRNAs were predicted as downstream targets of CASC19 under certain condition (CLIP Data: high stringency $(\geq 3)$ ). It was uncovered that miR-152-3p had the strongest binding ability for CASC19 (Fig. 3a). Furthermore, miR-152-3p expression was downregulated in C28/I2 cells triggered with IL-1 $\beta$ (Fig. 3b). The overexpression efficiency of miR-152-3p mimics was verified in Fig. 3c. Findings verified that miR-152-3p overexpression attenuated the luciferase activity of CASC19-Wt vectors but had no effects on CASC19-Mut vectors (Fig. 3d). Additionally, the expression of CASC19 and miR-152-3p was enriched in Ago2 group but not in IgG group, indicating CASC19 sponged miR-152-3p (Fig. 3e). To sum up, miR-152-3p was a sponge for CASC19.

\section{MiR-152-3p targeted DDX6}

In the next step, the potential mRNAs which could combine with miR-152-3p were investigated. The Venn diagram illustrated that 7 mRNAs (GADD45A, SLC25A44, DDX6, ATP2A2, PNPLA6, CTSA, and QKI) all existed in microT and TargetScan database (Fig. 4a). Among these mRNAs, DDX6 expression showed the largest decrease after miR-152-3p overexpression, thus DDX6 was selected for further study (Fig. 4b). Moreover, RT-qPCR indicated that DDX6 expression was upregulated in C28/I2 cells mediated with IL-1 $\beta$ (Fig. 4c). In addition, it was uncovered that miR-152-3p overexpression attenuated the luciferase activity of DDX6-Wt vectors but had no effects on DDX6-Mut vectors (Fig. 4d). Furthermore, the abundance of miR-152-3p and DDX6 was found in Ago2 group, suggesting miR-152-3p targeted DDX6 (Fig. 4e). To sum up, miR-152-3p combined with DDX6.

\section{CASC19 regulated proinflammatory cytokine production and cell apoptosis through DDX6}

To explore whether CASC19 regulated proinflammatory cytokine production and cell apoptosis through DDX6, rescue assays were performed. The upregulated expression of DDX6 was verified after overexpressing DDX6 (Fig. 5a). The reduced IL-6, IL-8, and TNF- $\alpha$ levels

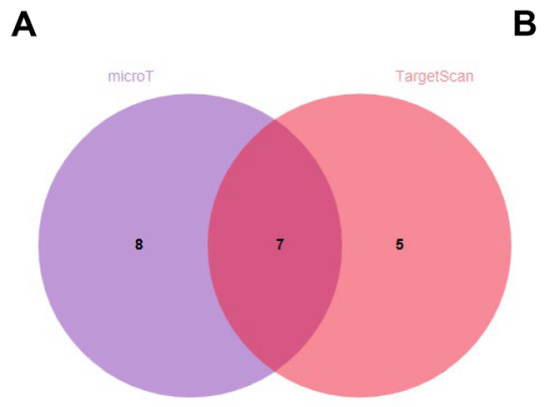

C

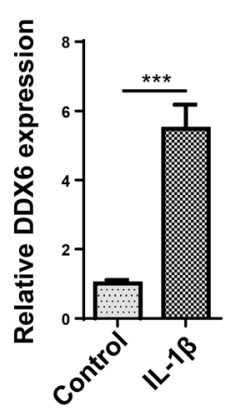

D

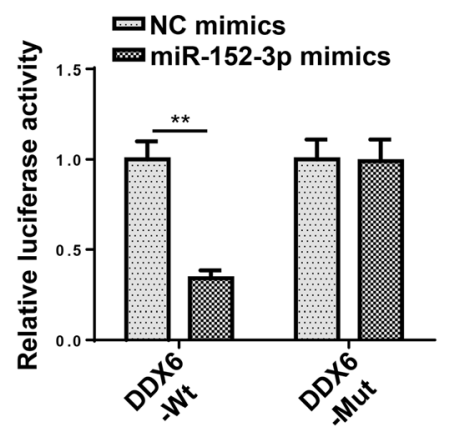

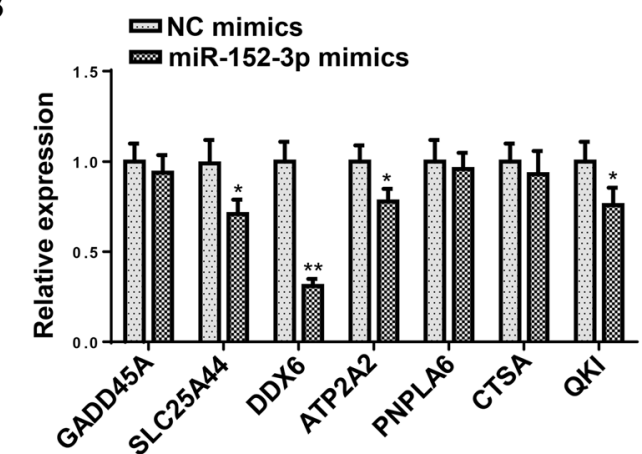

E

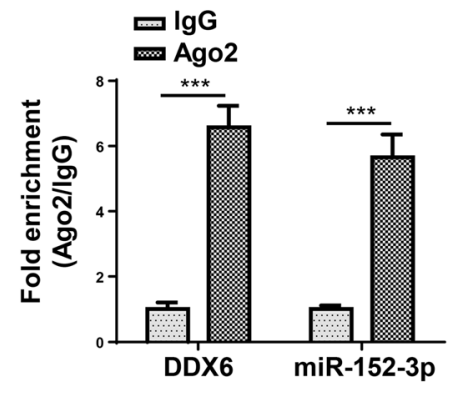

Fig. 4 MiR-152-3p targeted DDX6. a The Venn diagram displayed these mRNAs which could combine with miR-152-3p. b The selected mRNAs expression was detected after overexpressing miR-152-3p. c The DDX6 expression was examined through RT-qPCR assay. d The binding capacity between miR-152-3p and DDX6 was tested through luciferase reporter assay. e The interaction between miR-152-3p and DDX6 was evaluated through RIP assay. ${ }^{* *} P<0.01$ and ${ }^{* * *} P<0.001$ 


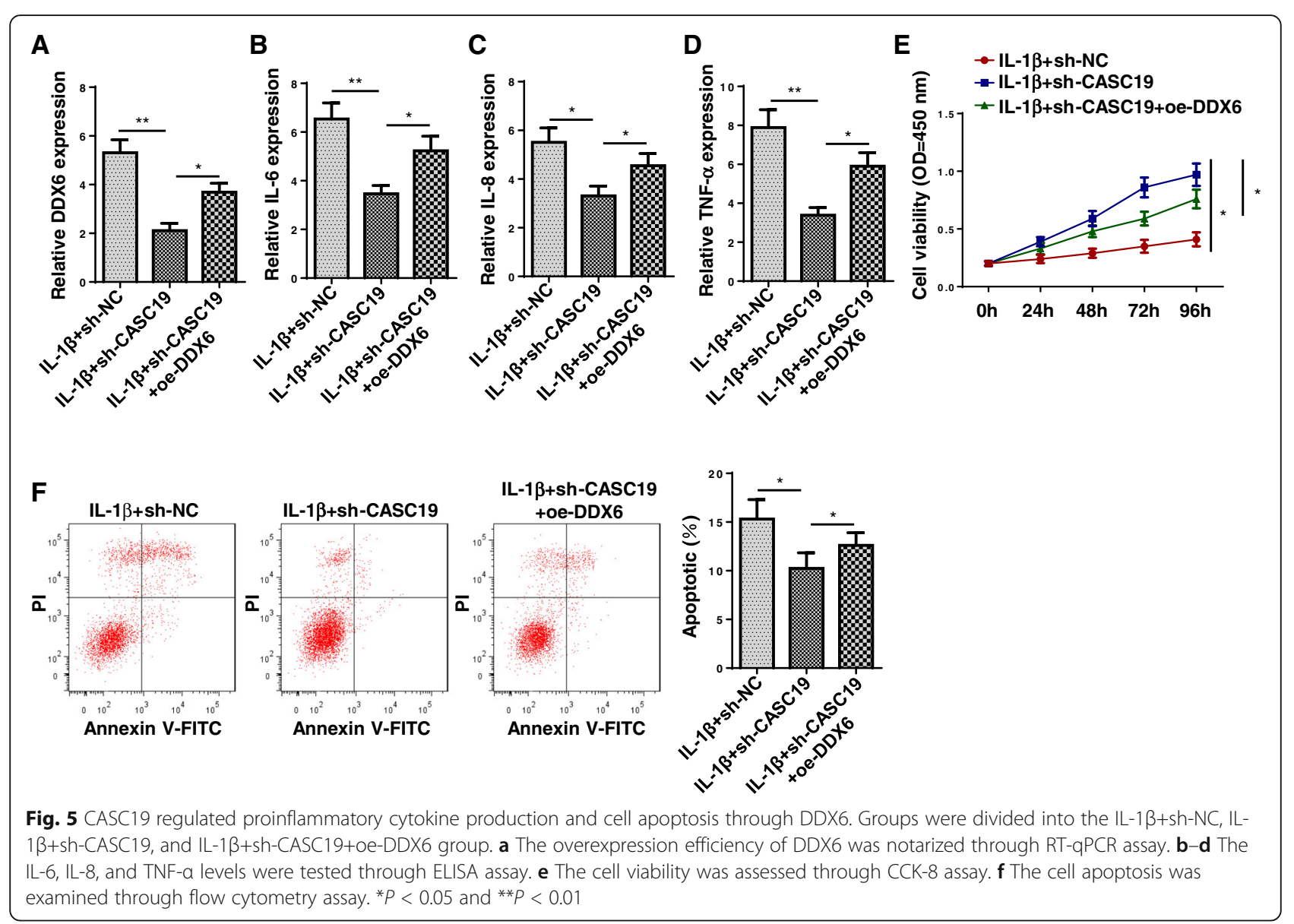

caused by repressing CASC19 could be reversed by upregulating DDX6 (Fig. 5b-d). As displayed in Fig. 5e, overexpression of DDX6 could offset the increased cell viability induced by CASC19 inhibition. In addition, the inhibitive effects of CASC19 suppression on cell apoptosis could be rescued by DDX6 overexpression (Fig. 5f). These results suggested that CASC19 regulated proinflammatory cytokine production and cell apoptosis through DDX6.

\section{Discussion}

With the fast development of science and technology, an increasing number of lncRNAs have been identified as crucial regulators in various diseases [27, 28]. CASC19 has been uncovered to be implicated in various cancers [14-16], but its function in OA remains indistinct. In this work, CASC19 exhibited higher expression in OA tissues and cell model. Moreover, inhibition of CASC19 weakened proinflammatory cytokine production and cell apoptosis.

LncRNAs are confirmed to be one pivotal player in competing endogenous RNA (ceRNA)-mediated mechanisms because they can act as sponges for miRNAs to regulate mRNA expression [29-31]. Interestingly, this regulatory mechanism is also widely involved in OA progression. For instance, IncRNA NEAT1/miR-181a/ GPD1L axis regulates chondrocyte proliferation, apoptosis, and inflammation [32]. In addition, IncRNA TUG1/miR-195/MMP-13 axis facilitates the degradation of chondrocyte extracellular matrix induced by OA [33]. LncRNA SNHG7 absorbs miR-214-5p to modulate PPARGC1B pathways and improves IL- $1 \beta$-induced OA [34]. Moreover, lncRNA MEG3 targets miR-93/TGFBR2 axis to retard extracellular matrix degradation in $\mathrm{OA}$ [35]. Through StarBase website, miR-152-3p was predicted to be a sponge for CASC19, and DDX6 was a downstream mRNA of miR-152-3p. Additionally, luciferase reporter and RIP assays elucidated that CASC19 absorbed miR-152-3p to release DDX6.

It has been reported that DEAD-box protein 6 (DDX6) plays an important role in various diseases. For example, RNA helicase DDX6 upregulates c-Myc expression by serving as an oncogene in gastric cancer [36]. Additionally, DDX6 exhibited higher expression and modulated by miR-124 in colon cancer [37]. MiR130 family modulates P-body protein DDX6 to modulate the hypoxia response signal [38]. In our study, results from rescue assays certified that DDX6 overexpression 
could reverse the effects of CASC19 suppression on chondrocytes apoptosis and proinflammatory cytokine production.

\section{Conclusions}

This study was the first to discover the function and related ceRNA regulatory mechanism of CASC19 in OA. Our findings revealed that CASC19 accelerated chondrocytes apoptosis and proinflammatory cytokine production to exacerbate $\mathrm{OA}$ development through regulating miR-152-3p/DDX6 axis, indicating CASC19 may be a promising target for OA treatment and providing a novel direction of improving OA therapeutic methods for orthopedists. Although our study highlighted a CASC19-regulated regulatory mechanism in osteoarthritis progression, it is still limited because of the small sample size. In the future, this study will be further improved by expanding the sample size and adding more in vitro and in vivo experiments.

\section{Abbreviations}

IncRNAs: Long non-coding RNAs; OA: Osteoarthritis; RT-qPCR: Reversetranscription polymerase chain reaction; CCK-8: Cell Counting Kit-8; shRNA: Short hair RNAs; miRNA: MicroRNA; DDX6: DEAD-box protein 6; FITC: Annexin V-fluorescein isothiocyanate; PI: Propidium iodide; Wt: Wildtype; Mut: Mutant; ELISA: Enzyme-linked immunosorbent assay; IL6: Interleukin-6; IL-8: Interleukin-8; TNF-a: Tumor necrosis factor-alpha

\section{Acknowledgements}

Not applicable.

\section{Authors' contributions}

CZ and LC designed the study. CZ and TH analyzed the data and prepared the figures. LC drafted the manuscript. The author(s) read and approved the final manuscript.

\section{Funding}

Not applicable.

\section{Availability of data and materials}

The datasets used and/or analyzed during the current study are available from the corresponding author on reasonable request.

\section{Declarations}

Ethics approval and consent to participate

This study was supported by the Human Ethics Committee of Changzhou Hospital of Traditional Chinese Medicine.

\section{Consent for publication}

Not applicable.

\section{Competing interests}

The authors declare that they have no competing interests.

\section{Author details}

'Department of Orthopedics, The Third Affiliated Hospital of Soochow University, Changzhou 213000, People's Republic of China. ${ }^{2}$ Department of Osteoarthritis, The Third Affiliated Hospital of Soochow University, Changzhou 213000, People's Republic of China. ${ }^{3}$ Department of Encephalopathy, Changzhou Hospital of Traditional Chinese Medicine, No. 25 Heping North Road, Changzhou 213000, People's Republic of China.
Received: 25 March 2021 Accepted: 8 June 2021

Published online: 22 June 2021

\section{References}

1. Pereira D, Ramos E, Branco J. Osteoarthritis. Acta Med Port. 2015;28(1):99106. https://doi.org/10.20344/amp.5477.

2. Allen KD, Choong PF, Davis AM, Dowsey MM, Dziedzic KS, Emery C, et al. Osteoarthritis: models for appropriate care across the disease continuum. Best Pract Res Clin Rheumatol. 2016;30(3):503-35. https://doi.org/10.1016/j. berh.2016.09.003.

3. Plotnikoff R, Karunamuni N, Lytvyak E, Penfold C, Schopflocher D, Imayama I, et al. Osteoarthritis prevalence and modifiable factors: a population study. BMC Public Health. 2015;15(1):1195. https://doi.org/10.1186/s12889-015-252 9-0

4. Bijlsma JW, Berenbaum F, Lafeber FP. Osteoarthritis: an update with relevance for clinical practice. Lancet. 2011;377(9783):2115-26. https://doi. org/10.1016/S0140-6736(11)60243-2.

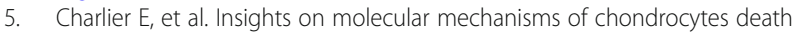
in osteoarthritis. Int J Mol Sci. 2016;17(12).

6. Charlier E, Deroyer C, Ciregia F, Malaise O, Neuville S, Plener Z, et al. Chondrocyte dedifferentiation and osteoarthritis (OA). Biochem Pharmacol. 2019;165:49-65. https://doi.org/10.1016/j.bcp.2019.02.036

7. Jarroux J, Morillon A, Pinskaya M. History, discovery, and classification of IncRNAs. Adv Exp Med Biol. 2017;1008:1-46. https://doi.org/10.1007/978981-10-5203-3_1.

8. Li X, Wu Z, Fu X, Han W. IncRNAs: insights into their function and mechanics in underlying disorders. Mutat Res Rev Mutat Res. 2014;762:1-21. https://doi.org/10.1016/j.mrrev.2014.04.002.

9. Nitsche A, Stadler PF. Evolutionary clues in IncRNAs. Wiley Interdiscip Rev RNA. 2017:8(1).

10. Li Y, Li Z, Li C, Zeng Y, Liu Y. Long noncoding RNA TM1P3 is involved in osteoarthritis by mediating chondrocyte extracellular matrix degradation. J Cell Biochem. 2019:120(8):12702-12. https://doi.org/10.1002/jcb.28539.

11. Li Y, Li S, Luo Y, Liu Y, Yu N. LnCRNA PVT1 regulates chondrocyte apoptosis in osteoarthritis by acting as a sponge for miR-488-3p. DNA Cell Biol. 2017; 36(7):571-80. https://doi.org/10.1089/dna.2017.3678.

12. Ye D, Jian W, Feng J, Liao X. Role of long noncoding RNA ZFAS1 in proliferation, apoptosis and migration of chondrocytes in osteoarthritis. Biomed Pharmacother. 2018;104:825-31. https://doi.org/10.1016/j.biopha.201 8.04.124.

13. Hu Y, Li S, Zou Y. Knockdown of LncRNA H19 relieves LPS-induced damage by modulating miR-130a in osteoarthritis. Yonsei Med J. 2019;60(4):381-8. https://doi.org/10.3349/ymj.2019.60.4.381.

14. Wang L, Lin C, Sun N, Wang Q, Ding X, Sun Y. Long non-coding RNA CASC19 facilitates non-small cell lung cancer cell proliferation and metastasis by targeting the miR-301b-3p/LDLR axis. J Gene Med. 2020; 22(12):e3254. https://doi.org/10.1002/jgm.3254.

15. Wu YJ, et al. Long non-coding RNA CASC19 promotes glioma progression by modulating the miR-454-3p/RAB5A axis and is associated with unfavorable MRI features. Oncol Rep. 2020;45(2):728-37. https://doi.org/10.3 892/or.2020.7876

16. Liang $H$, et al. CircRNA_0058063 functions as a ceRNA in bladder cancer progression via targeting miR-486-3p/FOXP4 axis. Biosci Rep. 2020:40(3).

17. Huang T, et al. LnCRNA CASC2 is up-regulated in osteoarthritis and participates in the regulation of IL-17 expression and chondrocyte proliferation and apoptosis. Biosci Rep. 2019;39(5).

18. Mohr AM, Mott JL. Overview of microRNA biology. Semin Liver Dis. 2015; 35(1):3-11. https://doi.org/10.1055/s-0034-1397344

19. Tian T, Wang J, Zhou X. A review: microRNA detection methods. Org Biomol Chem. 2015;13(8):2226-38. https://doi.org/10.1039/C4OB02104E.

20. Sondag GR, Haqqi TM. The role of microRNAs and their targets in osteoarthritis. Curr Rheumatol Rep. 2016;18(8):56. https://doi.org/10.1007/s11 926-016-0604-x

21. Wang R, Bai Z, Wen X, du H, Zhou L, Tang Z, et al. MiR-152-3p regulates cell proliferation, invasion and extracellular matrix expression through by targeting FOXF1 in keloid fibroblasts. Life Sci. 2019;234:116779. https://doi. org/10.1016/j.lfs.2019.116779.

22. Yin $\mathrm{T}$, et al. miR-152-3p modulates hepatic carcinogenesis by targeting cyclin-dependent kinase 8. Pathol Res Pract. 2019;215(6):152406.

23. Liu W, Wang Y, Qiu Z, Zhao R, Liu Z, Chen W, et al. CircHIPK3 regulates cardiac fibroblast proliferation, migration and phenotypic switching through 
the miR-152-3p/TGF- $\beta 2$ axis under hypoxia. PeerJ. 2020;8:e9796. https://doi. org/10.7717/peeri.9796.

24. Wan D, et al. miR-152 attenuates apoptosis in chondrocytes and degeneration of cartilages in osteoarthritis rats via TCF-4 pathway. Dose Response. 2020;18(4):1559325820946918.

25. Zhu JK, He TD, Wei ZX, Wang YM. LncRNA FAS-AS1 promotes the degradation of extracellular matrix of cartilage in osteoarthritis. Eur Rev Med Pharmacol Sci. 2018;22(10):2966-72. https://doi.org/10.26355/eurrev_201 805_15051.

26. Zhang Y, Wang F, Chen G, He R, Yang L. LncRNA MALAT1 promotes osteoarthritis by modulating miR-150-5p/AKT3 axis. Cell Biosci. 2019:9(1):54. https://doi.org/10.1186/s13578-019-0302-2.

27. Mallory AC, Shkumatava A. LncRNAs in vertebrates: advances and challenges. Biochimie. 2015;117:3-14. https://doi.org/10.1016/j.biochi.2015. 03.014 .

28. Zhang J, Zhu Y, Wang R. Long noncoding RNAs in respiratory diseases. Histol Histopathol. 2018:33(8):747-56. https://doi.org/10.14670/HH-11-966.

29. Li Y Y et al. Computational identification of cross-talking ceRNAs. Adv Exp Med Biol. 2018;1094:97-108. https://doi.org/10.1007/978-981-13-0719-5_10

30. Giza DE, Vasilescu C, Calin GA. MicroRNAs and ceRNAs: therapeutic implications of RNA networks. Expert Opin Biol Ther. 2014;14(9):1285-93. https://doi.org/10.1517/14712598.2014.920812.

31. Sanchez-Mejias A, Tay Y. Competing endogenous RNA networks: tying the essential knots for cancer biology and therapeutics. J Hematol Oncol. 2015; 8(1):30. https://doi.org/10.1186/s13045-015-0129-1.

32. Wang J, Xiao T, Zhao M. MicroRNA-675 directly targets MAPK1 to suppress the oncogenicity of papillary thyroid cancer and is sponged by long noncoding RNA RMRP. Onco Targets Ther. 2019;12:7307-21. https://doi.org/1 0.2147/OTT.S213371.

33. Tang LP, Ding JB, Liu ZH, Zhou GJ. LncRNA TUG1 promotes osteoarthritisinduced degradation of chondrocyte extracellular matrix via miR-195/MMP13 axis. Eur Rev Med Pharmacol Sci. 2018;22(24):8574-81. https://doi.org/1 0.26355/eurrev 201812 16620.

34. Xu J, Pei Y, Lu J, Liang X, Li Y, Wang J, et al. LncRNA SNHG7 alleviates IL-1 $\beta$ induced osteoarthritis by inhibiting miR-214-5p-mediated PPARGC1B signaling pathways. Int Immunopharmacol. 2021;90:107150. https://doi.org/1 0.1016/j.intimp.2020.107150.

35. Chen $\mathrm{K}$, et al. LnCRNA MEG3 inhibits the degradation of the extracellular matrix of chondrocytes in osteoarthritis via targeting miR-93/TGFBR2 axis. Cartilage. 2019:1947603519855759.

36. Taniguchi K, Iwatsuki A, Sugito N, Shinohara H, Kuranaga Y, Oshikawa Y, et al. Oncogene RNA helicase DDX6 promotes the process of c-Myc expression in gastric cancer cells. Mol Carcinog. 2018;57(5):579-89. https:// doi.org/10.1002/mc.22781.

37. Taniguchi K, Sugito N, Kumazaki M, Shinohara H, Yamada N, Matsuhashi N, et al. Positive feedback of DDX6/c-Myc/PTB1 regulated by miR-124 contributes to maintenance of the Warburg effect in colon cancer cells. Biochim Biophys Acta. 2015;1852(9):1971-80. https://doi.org/10.1016/j.bba dis.2015.06.022.

38. Saito K, Kondo E, Matsushita M. MicroRNA 130 family regulates the hypoxia response signal through the P-body protein DDX6. Nucleic Acids Res. 2011; 39(14):6086-99. https://doi.org/10.1093/nar/gkr194.

\section{Publisher's Note}

Springer Nature remains neutral with regard to jurisdictional claims in published maps and institutional affiliations.

Ready to submit your research? Choose BMC and benefit from:

- fast, convenient online submission

- thorough peer review by experienced researchers in your field

- rapid publication on acceptance

- support for research data, including large and complex data types

- gold Open Access which fosters wider collaboration and increased citations

- maximum visibility for your research: over $100 \mathrm{M}$ website views per year

At $\mathrm{BMC}$, research is always in progress.

Learn more biomedcentral.com/submissions 